\title{
REAL-TIME ROTOR BAR CURRENT MEASUREMENTS USING BLUETOOTH TECHNOLOGY FOR A BRUSHLESS DOUBLY-FED MACHINE (BDFM)
}

\author{
P. C. Roberts, E. Abdi Jalebi, R. A. McMahon and T. J. Flack \\ Engineering Department, University of Cambridge, Trumpington street, Cambridge, CB2 1PZ, UK \\ E-mail: pcr20@cam.ac.uk; fax: +44 (0)1223 332662
}

\begin{abstract}
The Brushless Doubly Fed Machine (BDFM) shows economic promise as a variable speed drive or generator. The optimization of the machine and model-based control strategies both rely on machine models, and the experimental verification of these models. To date, dynamic measurements of rotor quantities have not been possible. The authors present a system of measuring rotor bar currents in real time using a Rogowski coil to detect the current and recently developed Bluetooth wireless technology to transmit the data from the moving rotor to a computer. Experimental data collected from the system are included.
\end{abstract}

\section{INTRODUCTION}

Research into potential applications for the BDFM has accelerated over the last decade or so. The machine has attracted attention as a variable speed drive and as a generator in applications where the prime mover speed is variable, such as in wind turbines. For variable speed operation one of the machine's stator windings is connected to the fixed frequency mains or grid and other stator winding is supplied from an inverter. The rating of the inverter is only a fraction of rating of the machine so there are potential savings in system cost. At present, the doubly fed induction generator is widely used in wind turbines, as it also enables the use of a fractionally rated inverter. However, the BDFM has the advantage of avoiding the problems associated with brush gear, making the BDFM particularly attractive for offshore wind turbines.

The general construction of a BDFM has similarities with that of an induction motor but the rotor is of special design. The machine has two stator windings producing fields of dissimilar pole numbers and the rotor is specially designed to couple between the two fields. Normally the BDFM operates as a synchronous machine with a shaft speed related to the frequencies of the supplies to the two stator windings. Details of the theory and operation of the machine are given in [1,2] and references therein.

Although experimental results on practical BDFMs have been reported, for example from a frame size 160 machine in [2], there has not been any work on the measurement of rotor currents in the BDFM. The design of the rotor is critical to good performance and direct measurements of rotor currents would help to build confidence in rotor performance as machine sizes increase. However, rotor currents cannot be directly measured by conventional techniques. As well as verifying theoretical predictions, measurements of rotor currents would facilitate the acquisition of accurate parameter values for machine models. This latter task is particularly difficult with the BDFM as deducing rotor values from measurements of stator quantities is prone to errors. Furthermore, in [3] the authors present a control strategy which requires knowledge of the rotor bar current in real-time, so monitoring rotor bar currents during operation is of considerable advantage.

The design of a system to measure rotor currents is complicated firstly because the rotor is moving, and secondly because of strong electro-magnetic fields in the machine air-gap and end region. Normally one winding will be fed from an inverter and this will introduce interference at frequencies related to the switching frequency of the inverter. Apart from the obvious difficulty of extracting data signals from a moving rotor the centripetal acceleration acting on the transducer is around $1000 \mathrm{~m} / \mathrm{s}^{2}$ at $1000 \mathrm{rpm}$.

The authors therefore propose a system of measuring rotor bar current directly with a Rogowski coil, using the recently developed Bluetooth wireless technology to transmit the signal from the moving rotor back to a computer for logging and analysis.

The requirements of the sensor are to measure currents up to 3000 A peak-to-peak, from $1 \mathrm{~Hz}$ to $100 \mathrm{~Hz}$. This frequency range is required for the BDFM as the machine runs with a wide range of slips in normal operation, unlike a standard induction motor. 


\section{SYSTEM DESIGN AND SPECIFICATION}

\subsection{System}

The measurement system comprises the sections shown diagrammatically in figure 1 .

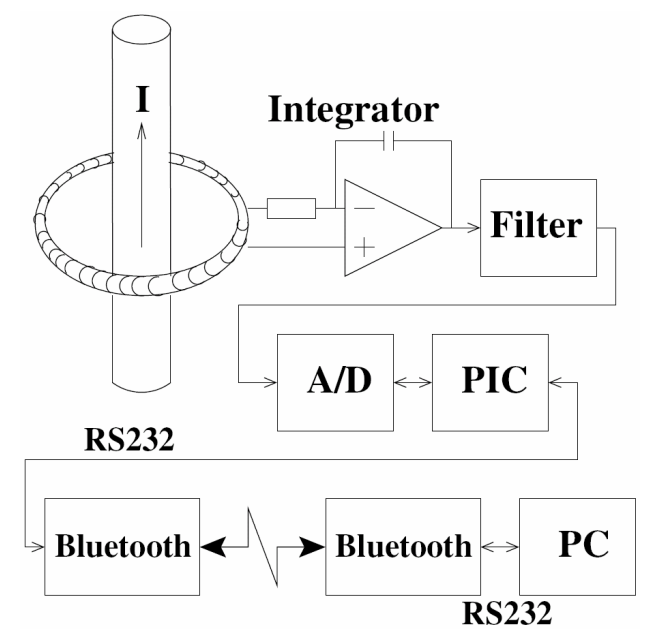

Figure 1: Functional Block Diagram of the System

\subsection{Rogowski coil current transducer}

A Rogowski coil is a low noise, air-cored current transducer. Rogowski coils are beginning to find application within electrical machines due to their small size and low insertion loss as compared to a current transformer [4].

For this application a Rogowski coil was chosen as the current transducer for the following reasons:

- Air cored (therefore a small cross-section is possible. This is necessary as the coil is to be wrapped around a rotor bar)

- Immune to interference

- Can easily be made in an openable form (so it can be retro-fitted to a bar)

- Negligible insertion loss

A small Rogowski coil, as shown in figure 2, was manufactured to the specifications given in table 1 .

A Rogowski coil is essentially a toroidal coil, and therefore the induced voltage in the coil is given as follows:

$$
v_{\text {coil }}=-\mu_{0} n A \frac{d i}{d t}
$$

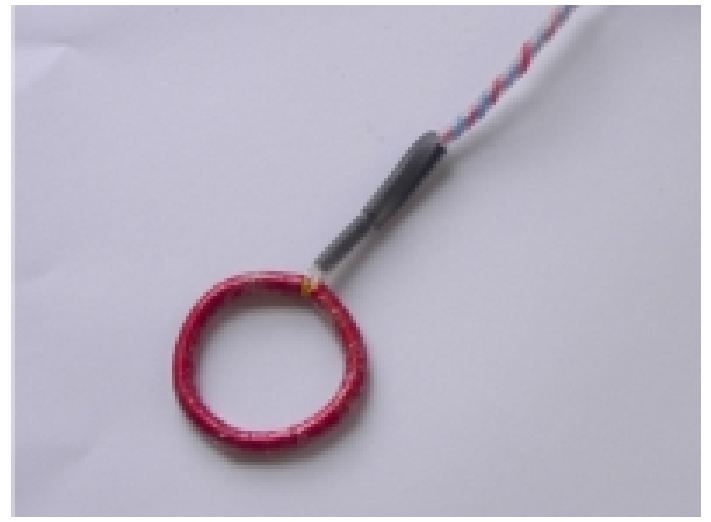

Figure 2: The prototype Rogowski coil

\begin{tabular}{|c|c|}
\hline Coil parameter & Specification \\
\hline Coil length $(\mathrm{mm})$ & 107 \\
\hline Turns per metre & 4190 \\
\hline Self inductance $(\mathrm{mH})$ & 9.18 \\
\hline Resistance $(\Omega)$ & 2.68 \\
\hline Total turns & 340 \\
\hline Sensitivity $(\mathrm{nV} / \mathrm{AHz})$ & 70 \\
\hline
\end{tabular}

Table 1: The prototype Rogowski coil specifications

where $i$ is the instantaneous current, $n$ is the number of turns per metre, and $A$ is the coil cross-sectional area. The sensitivity of the Rogowski coil is defined by $\mu_{0} n A$ and for the prototype coil is about $70 \mathrm{nV} / \mathrm{AHz}$.

\subsection{Integrating amplifier and active filter}

While a Rogowski coil is inherently low noise if the turns are sufficiently closely spaced, the signal level produced is very small. The output of the coil passes to an integrator. The operational amplifier must be carefully chosen to have a low input offset voltage to allow operation at high gain at low frequencies [5]. It must also have low noise and sufficient bandwidth to ensure accurate integration over the frequency range of interest.

The signal was then band-limited to minimise noise using a $1 \mathrm{kHz}$ low pass 2 pole Butterworth VCVS (voltagecontrolled voltage-source) active filter. The operational amplifiers have to operate from a low supply voltage and consume as little power as possible to extend battery life. The Analog Devices AD8552 was used for both the integrating amplifier and active filter.

A simplified representation of the circuit is shown in figure 3 . A $50 \mathrm{~Hz}$ sinusoidal signal with a $5 \mathrm{kHz}$ noise signal 
super-imposed was applied to the circuit and the output is shown in figure 4.

Since the maximum output voltage $\left(\mathrm{V}_{\text {out(max })}\right)$ of the AD8552 is $3 \mathrm{~V}$, the maximum current the sensor can measure, $I_{\max }$, can be obtained from equation 2 .

$$
I_{\max }=\frac{V_{\text {out }(\max )}}{A_{V(F)} \cdot A_{V(A)} \cdot S_{R}}
$$

Where $A_{v(F)}$ is the active filter gain, $A_{v(A)}$ is the integrator gain, and $S_{R}$ is the Rogowski coil sensitivity. Considering the values in table 2, the maximum current the sensor can measure is $I_{\max }=3300$ A peak-to-peak.

Figure 5 shows the nominal transfer function of the integrator and filter circuit. High frequency effects of the Rogowski coil are not significant at the frequencies of interest. This design gives a bandwidth of $0.5 \mathrm{~Hz}<f<130$ $\mathrm{Hz}$ with a magnitude error of less than $1.5 \%$, and a phase error of less than $10^{\circ}$. At $50 \mathrm{~Hz}$ the magnitude error is less than $0.3 \%$, and the phase error less than $4^{\circ}$.

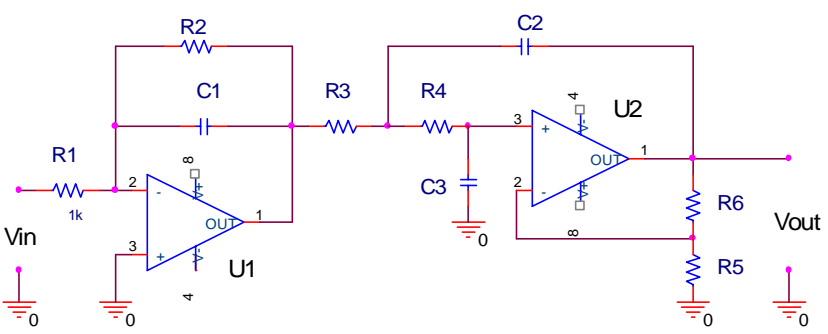

Figure 3: Integrating amplifier and active filter

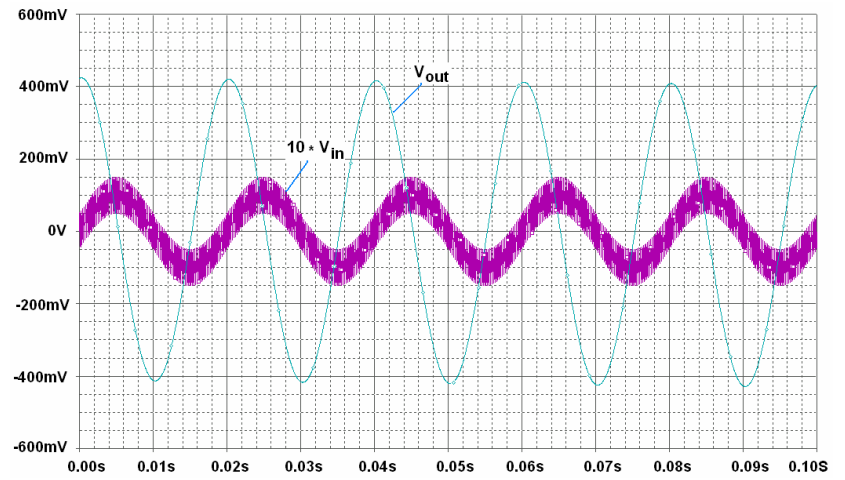

Figure 4: Real time simulation: circuit output for $50 \mathrm{~Hz}$ signal super-imposed with $5 \mathrm{kHz}$ noise
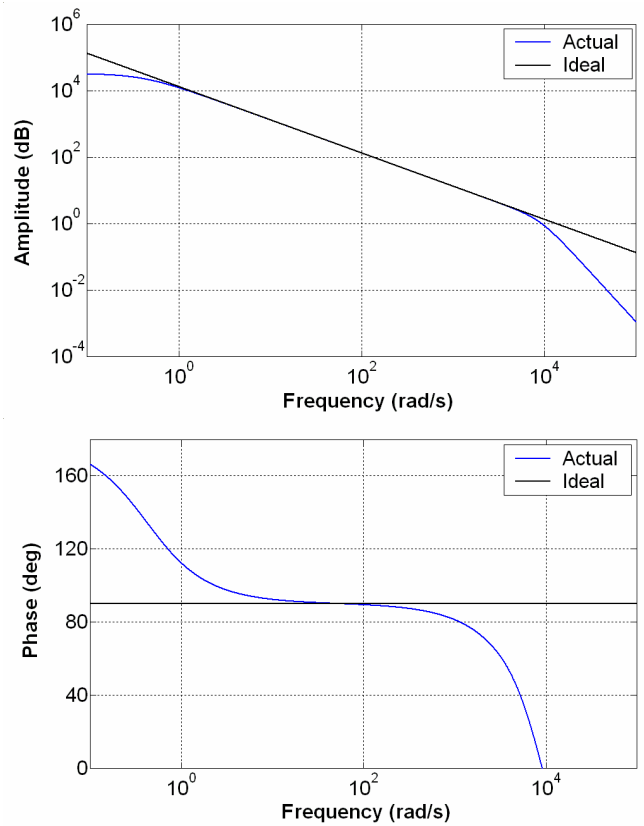

Figure 5: Integrator and filter transfer function

\begin{tabular}{|c|c|}
\hline Variable & Value \\
\hline$A_{v(F)}$ & $1.6 \mathrm{~V} / \mathrm{V}$ \\
\hline$A_{v(A)}$ & $8200 \mathrm{VHz} / \mathrm{V}$ \\
\hline$S_{R}$ & $7 \times 10^{-8} \mathrm{~V} / \mathrm{AHz}$ \\
\hline
\end{tabular}

Table 2: variables used to calculate the maximum current

\subsection{Analogue to digital conversion}

The output of the current probe is digitised using a 10-bit analogue-to-digital converter (ADC), which is contained in the microcontroller. The on-chip ADC was used for simplicity and to reduce the parts count. The prototype uses a Microchip PIC16F877 microcontroller to perform analogue to digital conversion and to put the data in a serial form. The serial connection profile is shown in table 3 . Since each sample data from the output of the ADC has ten bits, two bytes have to be transmitted for each sample. The system runs at $57.6 \mathrm{kbaud}$, which gives a sample rate of $3.2 \mathrm{kHz}$.

\begin{tabular}{|c|c|}
\hline Parameters & Serial specifications \\
\hline Baud rate & $57600 \mathrm{kbit} / \mathrm{s}$ \\
\hline Data bits & $8 \mathrm{bits}$ \\
\hline Stop bit & $1 \mathrm{bit}$ \\
\hline Parity & None \\
\hline
\end{tabular}

Table 3: Serial connection profile 


\subsection{Bluetooth wireless data transmission}

The Bluetooth wireless technology was created to solve a simple problem - replacing cables with radio links. The technology encompasses a simple low-cost, low-power, global radio system for integration into mobile devices. The challenge in rotor bar current measurement is to transmit the digitised data from the moving rotor to the computer and Bluetooth offers a solution to this problem. The radio frequency signal from the measurement system must propagate either through small apertures in the machine casing or through small antenna brought out from the shaft. This suggests using a radio system designed for mobile use, such as Bluetooth.

Bluetooth is one of a number of recent wireless protocols. Bluetooth is seen as a replacement for the infra-red (IrDA) standard commonly found in laptop computers and mobile phones. Bluetooth uses a $2.4 \mathrm{GHz}$ radio link for short-range connections with high interference immunity, achieved through error correction coding and frequency hopping [6]. Bluetooth was chosen for this application, in preference to other wireless standards because of its high interference immunity, low cost, and ease of implementation.

In order to facilitate the digital design of the system modules based on Cambridge Silicon Radio's (CSR) BlueCore chip were utilised. CSR provide software for these modules which implements RS232 over Bluetooth. Although RS232 can only utilise a fraction of the total bandwidth available on the Bluetooth link (1 Mbit/s) its ease of use made it the best choice for this initial design.

\subsection{Power supply}

The circuitry is supplied by three rechargable AA cells. This supply voltage is stabilised by two linear regulators to give separate $3.3 \mathrm{~V}$ supplies for analog and digital parts. The normal operating current is about $87 \mathrm{~mA}$, which gives around 20 hours operation before recharging is required. Recharging in situ is possible via connections brought out through a hole in the shaft.

\section{EXPERIMENTAL RESULTS}

After calibration, the system was tested on a frame size 180 BDFM. The stator and frame are from a commercial $18.5 \mathrm{~kW}$, four-pole induction motor and the rotor construction is similar to that described by Williamson and Ferreira [2], comprising six sets of nested loops. Table 4 gives further details for the machine. The Rogowski coil was attached around a bar in the outer loop one of the nests of three concentric loops. Figure 6 shows the circuit installed on the rotor of the machine.

The noise level of the received signal was around $3 \mathrm{~A}_{\mathrm{rms}}$. The system worked without any noticeable data errors over distances up to about $5 \mathrm{~m}$.

In order to demonstrate the performance of the measurement system and to show how it can be used to gain insight into BDFM operation, tests were carried out in both synchronous and asynchronous modes. Normal operation is in the synchronous mode but operation in the asynchronous mode can occur under fault conditions, and can give additional data on machine parameters.

\begin{tabular}{|c|c|}
\hline Frame size & D180 \\
\hline Stator 1 poles & 4 \\
\hline Stator 2 poles & 8 \\
\hline Rotor design & $\begin{array}{c}\text { 6 nests of 3 concentric loops } \\
\text { with one common end ring }\end{array}$ \\
\hline
\end{tabular}

Table 4: BDFM main specifications

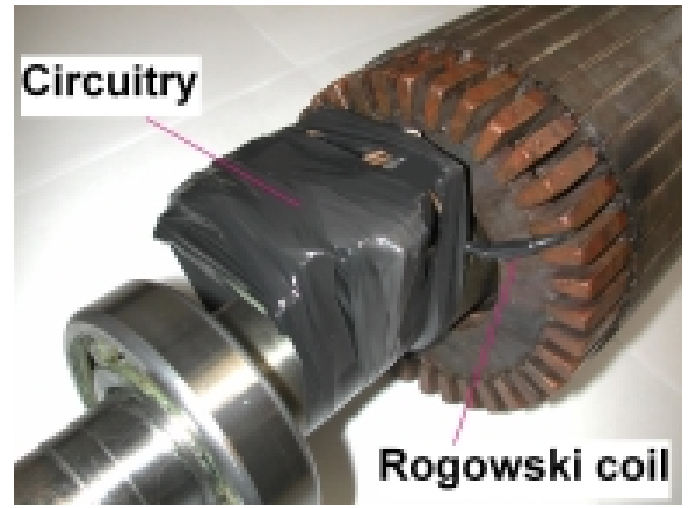

Figure 6: Rogowski coil and accompanying circuitry on BDFM rotor

\subsection{Asynchronous mode}

The BDFM can produce asynchronous induction torques in several ways. In the most basic configuration, one of the stator windings is excited and the other is left open circuit. Under these conditions the machine acts as an induction motor with the pole number of the excited stator winding. A well-designed rotor for a BDFM is optimized for crosscoupling between two fields of different pole numbers and is likely to give relatively low self-induction torques. The BDFM is not intended for use in this mode but it can be used to obtain machine parameters and insight into the performance of the machine.

The 8-pole stator winding was excited from a $270 \mathrm{~V}$ power supply while the 4-pole winding was open circuit. This 
excitation gives an air-gap flux of approximately $0.35 \mathrm{~T}_{\mathrm{rms}}$. Figure 7 shows an example current waveform of 1000 samples recorded from the outer loop of a single nest of the rotor running in BDFM induction mode at $580 \mathrm{rpm}$. The rotor current frequency can be calculated by:

$$
f_{r}=\left(n_{s y n}-n_{\text {mech }}\right) \frac{p}{60}
$$

where $f_{r}$ is the rotor current frequency, $n_{s y n}$ is the synchronous speed, $n_{\text {mech }}$ is the rotor speed and $p$ is the number of pole pairs. From the equation 3 , the frequency of the rotor current is $11.33 \mathrm{~Hz}$ at $580 \mathrm{rpm}$. The rotor bar frequency from the figure 7 is about $11.4 \mathrm{~Hz}$, which agrees with the theoretical calculation.

The BDFM was run in induction mode at different speeds. The relationship between torque, rotor current and slip in induction machines is shown in equation 4 [7]:

$$
T_{\text {mech }}=\frac{1}{\omega_{\text {syn }}} \frac{R_{2}^{\prime}}{s} I_{r}^{\prime 2}
$$

where $T_{\text {mech }}$ is the mechanical torque, $\omega_{s y n}$ is the synchronous angular velocity, $R_{2}^{\prime}$ is the rotor resistance, $s$ is the slip and $I_{r}^{\prime}$ is the referred rotor current.

The referred rotor current is proportional to the bar current. Slip and $I_{b}{ }^{2} / \mathrm{s}$ are calculated using $\omega_{s y n}=78.5 \mathrm{rad} / \mathrm{s}$, equivalent to $750 \mathrm{rpm} . I_{b}$ is the rotor bar current measured with the current probe. Figure 8 shows the $I_{b}^{2} / s$ plotted versus speed. The curve is very similar to the torque-speed characteristic of induction machines.

\subsection{Synchronous Mode}

A BDFM is normally operated in its synchronous mode with its shaft speed given by

$$
\omega_{\text {mech }}=2 \pi \frac{f_{s_{1}}+f_{s_{2}}}{p_{1}+p_{2}}
$$

where $p_{1}$ and $p_{2}$ are the pole pair numbers of the two stator windings, and $f_{s 1}$ and $f_{s 2}$ are the corresponding exciting frequencies. When one winding is supplied with dc, and the other with $50 \mathrm{~Hz}$ the machine will run at $500 \mathrm{rpm}$, also known as the natural speed. In the tests, the 8-pole winding was excited from the $50 \mathrm{~Hz}$ mains, and the 4-pole winding was supplied with DC equivalent to $7 \mathrm{~A}_{\mathrm{rms}}$ per phase. As the applied torque is varied, the load angle changes and the rotor and 8-pole stator current adjust accordingly. The variation of rotor and stator currents is shown in figure 9 .

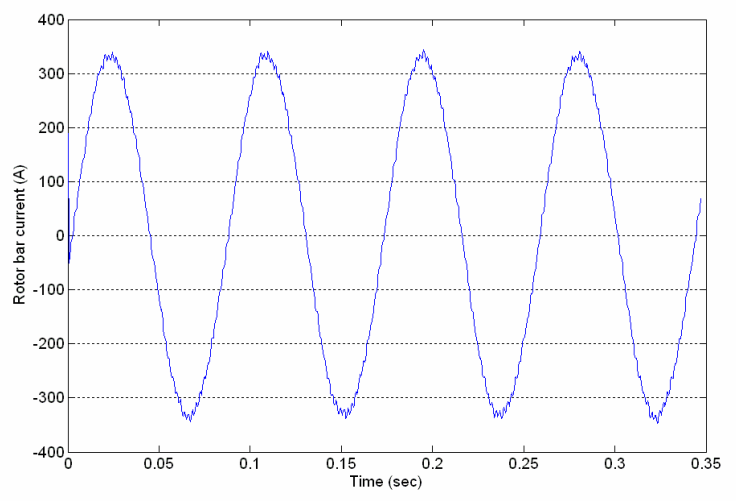

Figure 7: Rotor bar current for BDFM induction mode at 580rpm

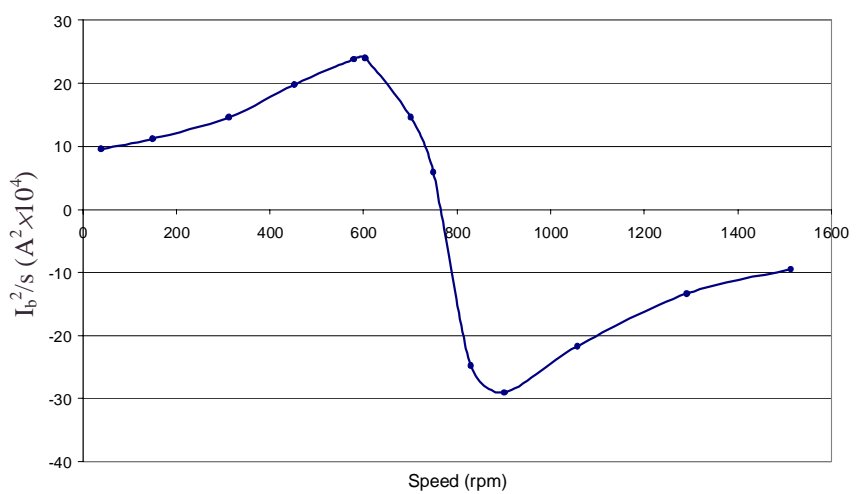

Figure 8: BDFM asynchronous mode characteristics

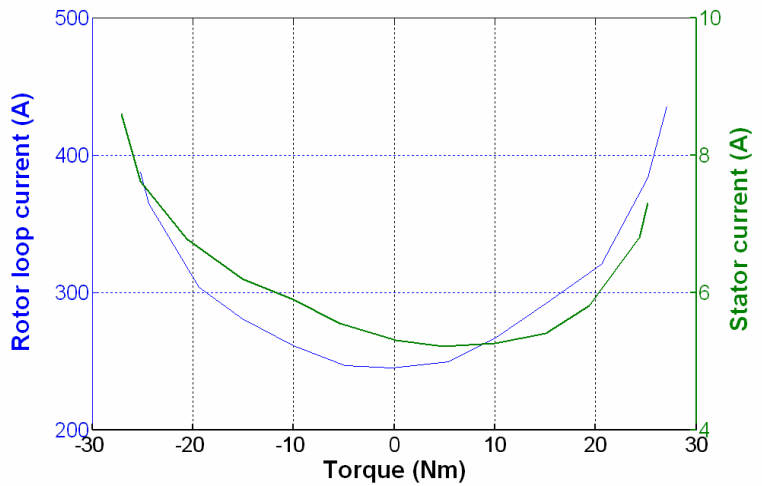

Figure 9: Variation of rotor and 8-pole stator current with torque at $500 \mathrm{rpm}$

\section{CONCLUSIONS}

The paper presents the design and evaluation of the realtime rotor bar current measurement system which uses a Rogowski coil as a current transducer and a Bluetooth wireless link to transmit data back to the bench. The 
measurement system has high accuracy, good immunity to noise, and low power consumption. By using commercially available Bluetooth modules the cost is moderate. The application to the BDFM shows the feasibility of the approach, which may find application in the wider field of electrical machines. The approach can also be used when electrical isolation is required, as in high voltage machines.

Applying the system to the BDFM allows the rotor current to be monitored, for example as the applied torque changes. This is valuable both in verifying theoretical predictions and in obtaining machine parameters for equivalent circuits. The authors plan to put Rogowski coils around all three loops in a nest, with the signal multiplexed over a single Bluetooth link. It will then be possible to confirm the predicted distribution of current between the loops. Finally, the system has the potential to be part of a control system of the type proposed in [3].

\section{ACKNOWLEDGEMENTS}

The authors would like to thank FKI Energy Technology for their continuing support of research into the BDFM, particularly the subsidiary companies Laurence, Scott \& Electromotors Ltd, Marelli Motori Spa and FKI Industrial Drives Ltd. We would also like to thank Cambridge Silicon Radio for their support and their kind provision of the Bluetooth modules.

\section{REFERENCES}

[1] S. Williamson, A. C. Ferreira, A. K. Wallace. "Generalised Theory of the Brushless Doubly-Fed Machine. Part 1: Analysis", Electric Power Applications, IEE Proceedings, 144, pp. 111-122, (1997).

[3] S. Williamson, A. C. Ferreira. "Generalised Theory of the Brushless Doubly-Fed Machine. Part 2: Model Verification and Performance", Electric Power Applications, IEE Proceedings, 144, pp. 123-129, (1997).

[3] P. C. Roberts, T. J. Flack, J. M. Maciejowski, R. A. McMahon. "Two Stabilising Control Strategies for the Brushless Doubly-Fed Machine (BDFM)", International Conference of Power Electronics, Machines and Drives, pp. 341-346, (2002).

[4] N. Karrer, P. Hofer-Noser. "A New Current Measuring Principle for Power Electronic Applications", The 11th International Symposium on Power Semiconductor Devices and ICs, ISPSD'99, pp. 279-282, (1999).

[5] Z. Mingjuan, D. J. Perreault, V. Caliskan, T. C. Neugebauer, S. Guttowski, J. G. Kassal. "Design and evaluation of an active ripple filter with Rogowski-coil current sensing", 30th Annual IEEE Power Electronics Specialists Conference, PESC 99, 2, pp. 874 880, (1999).

[6] B. Chatschik. "An Overview of the Bluetooth Wireless Technology", IEEE Communications Magazine, 39, pp. 86-94, (2001).

[7] P. C. Sen. "Principles of Electric Machines and Power Electronics", $2^{\text {nd }}$ edition, New York, 1997. 